\title{
COVID 19 Outbreak: Potential of Biochemistry Speciality
}

\author{
Ashok Kumar Ahirwar ${ }^{1} \cdot$ Priyanka Asia $^{1} \cdot$ Apurva Sakarde $^{1} \cdot$ Shilpa Bhardwaj $^{2}$
}

Received: 29 March 2020/Accepted: 3 April 2020/Published online: 18 April 2020

(C) Association of Clinical Biochemists of India 2020

COVID-19, a viral infection has been spreading all over the world like a pandemic and India is not untouched by it.

WHO has declared it a public health emergency of international concern on 20th January 2020 [1]. World power such as USA, Canada and whole Europe is unable to control COVID-19 outbreak despite having best health care facility in world.

The Indian subcontinent has also been hit hard due to current COVID-19 outbreak. COVID-19 is primarily reported in those individuals who have travel history abroad and close contact to confirmed/suspected cases. As of now, this pandemic in India is in stage 2 as there is no report regarding community transmission [2].

This outbreak has negatively impacted India's health, economy, development and sense of security. The outbreak seems to be unstoppable due to overcrowding, lack of awareness, weak health care system including molecular diagnostic services [1].

Non-availability of laboratory services make it extremely difficult to combat COVID-19 pandemic in India. India need to better prepare to detect these cases through an efficient surveillance services including laboratory services, which are extremely critical in containing the initial phase of COVID-19 outbreak.

Setting up of adequate equipped and dedicated health facility including diagnostic services is the need of the

Ashok Kumar Ahirwar

drashoklhmc@gmail.com

1 Department of Biochemistry, All India Institute of Medical Sciences, Nagpur, Maharashtra 441108, India

2 Department of Biochemistry, Rajiv Gandhi Super Specialist Hospital, New Delhi 110093, India hour. Each tertiary care center/medical college should have at least such facility.

It is also desirable to bring all diagnostic expertise of tertiary health care and teaching hospital such as Biochemistry, Microbiology and Pathology department in one common platform for one common goal to contain COVID-19 pandemic.

COVID-19 virus testing is being done by Real time RT PCR and target gene is RdRp gene. Laboratory testing is the only means to detect COVID-19 infection in symptomatic and asymptomatic viral infections.

Biochemistry speciality could be used for strategic acceleration of available diagnostic services. The biochemist has also been very well versed with molecular diagnostic techniques such as Real time RT-PCR and expertise. A person with $\mathrm{MSc} / \mathrm{MD} / \mathrm{PhD}$ in biochemistry is having deep insight in molecular biology and its technique such as Real time RT PCR, not less than a microbiologist or pathologist. Hence biochemist's expertise could also be used for setting large number of molecular diagnostic lab across India to meet its current requirement.

As of now, biochemist's expertise is underutilized at this time of urgent requirement.

As of 28th March 2020, total government laboratories approved by ICMR, New Delhi for COVID-19 testing are 122 out of which 113 are operational laboratories and 09 laboratories are in the process of operationalization [3]. ICMR has also approved 47 private laboratories chain all over India [4]. As to tackle the current 1.33 billion population of India, it seems to be inadequate if outbreak enters in phase 3 of pandemic that is community transmission. Even affordability and approachability of diagnostic facility is a big question in current scenario. The supply of equipments such as Real Time PCR and required reagents has to be maintained to keep pace with COVID-19 
outbreak. The current medical education system especially post-graduation in laboratory sciences must incorporate training and competency in Real Time PCR and molecular diagnostic techniques in curriculum to combat future outbreak.

It also needs political commitment, institutional and inter departmental collaborations and most important community participation to fight against COVID-19 pandemic.

\section{References}

1. Tandon PN. COVID-19: Impact on health of people \& wealth of nations. Indian J Med Res. 2020; https://doi.org/10.4103/ijmr. IJMR_664_20.
2. Bhatia R. Need for integrated surveillance at human-animal interface for rapid detection \& response to emerging coronavirus infections using One Health approach. Indian J Med Res. 2020; https://doi.org/10.4103/ijmr.IJMR_623_20.

3. ICMR, COVID-19. List of Government Laboratories for COVID19 Testing (As on 18/03/2020), Available from https://icmr.nic.in/ sites/default/files/upload_documents/Functional_labs_as_on_ 28032020_v1.pdf. Accessed 29 Mar 2020.

4. ICMR, COVID-19 List of Private Laboratories for COVID-19 Testing (As on 18/03/2020), Available from https://icmr.nic.in/ sites/default/files/upload_documents/Privat_Labs_28032020.pdf. Accessed 29 Mar 2020.

Publisher's Note Springer Nature remains neutral with regard to jurisdictional claims in published maps and institutional affiliations. 